\title{
Em Busca do Direito Fundamental à Felicidade: a Legitimidade Constitucional da Implementação dos Direitos Prestacionais-Sociais pelo Estado Brasileiro
}

\begin{abstract}
HELTON KRAMER LUSTOZA
Mestre em Direito Constitucional pela UNIBRASIL, com estudos na UFPR, Especialista em Direito Tributário e Financeiro, Graduado em Direito pela Universidade Positivo, Pesquisador Integrante do Grupo de Estudos Justiça Tributária e Atividade Econômica na PUCPR, Professor dos Cursos de Graduação (PUC-PR e Facear) e Especialização (ICEET), Instrutor de Cursos de Qualificação e Aperfeiçoamento de Servidores Públicos pelo Cotef/RJ, Professor da Escola Superior da Advocacia - ESA, Membro da Comissão de Direito Tributário da OAB-PR, Diretor Provisório do CEAF-SJP, Membro Julgador do Conselho de Contribuintes Municipal, Procurador do Município de São José dos Pinhais/PR.
\end{abstract}

Submissão: 10.01 .2012

Decisão Editorial: 24.04.2012

RESUMO: 0 artigo visa a abordar as bases teóricas que influenciaram a construção do Estado Democrático de Direito brasileiro. A pesquisa irá desencadear os fundamentos e a legitimidade para que o Estado seja o protagonista na missão de implementar os direitos prestacionais-sociais. Buscou-se demonstrar que a felicidade dos cidadãos está ligada, de alguma forma, com a plenitude da dignidade da pessoa humana, que, por sua vez, se compõe da realização da liberdade e da igualdade. E a missão do Estado é combater as desigualdades sociais, fortalecendo a vida digna de seus cidadãos, o que torna mais desafiante 0 caminho da implementação dos direitos prestacionais-sociais.

PALAVRAS-CHAVE: Felicidade; Constituição; Estado; dignidade; justiça.

ABSTRACT: The article aims to address the theoretical foundations that influenced the construction of a democratic state in Brazil. The research will trigger the foundations and legitimacy for the state to be the protagonist in the mission of implementing the prestacional-social rigths. We sought to demonstrate that the happiness of the citizens is somehow connected with the fullness of the Dignity of Man, which in turn, consist of the realization of freedom and equality. The mission of the State is to combat social inequality, strengthening the dignified life of its citizens, which makes it more challenging the path of implementing the prestacional-social rigths.

KEYWORDS: Happiness; Constitution; State; dignity; justice.

SUMÁRIO: I - As bases teóricas da formação do Estado Democrático brasileiro; II - A influência da teoria da justiça como equidade de John Rawls; III - A implementação dos direitos prestacionais-sociais como condição da dignidade da pessoa humana; Considerações finais; Referências. 


\section{I- AS BASES TEÓRICAS DA FORMAÇÃO DO ESTADO DEMOCRÁTICO BRASILEIRO}

Gramaticalmente, a terminologia "justiça" denota o significado de "a faculdade de julgar segundo o direito e melhor consciência"1. Assim, tradicionalmente, essa palavra fornece uma ideia motivadora, uma espécie de sentimento que funciona como justificativa para ações humanas em busca de mudanças a fim de corrigir alguma distorção social ${ }^{2}$, muito utilizada como justificativa de desobediências civis, guerras, revoluções, etc.

Um dos debates mais importantes no direito constitucional moderno diz respeito aos fundamentos de justiça da ação estatal; seria a tentativa de se identificar qual é a teoria da justiça que foi adotada pela Constituição Federal de 1988. Ao momento em que o preâmbulo da Constituição elege como objetivo do Estado Democrático de Direito brasileiro, entre outros, a justiça, ela está condicionando as condutas estatais para tal finalidade. Mas a dúvida surge quando se analisa a legitimidade estatal diante dos casos concretos, em que, cotidianamente, se verifica uma insegurança quanto à constatação da legitimidade da presença do Estado nas decisões dos rumos da sociedade.

A necessidade de se reconhecer a teoria da justiça adotada pela Carta Constitucional pauta-se no impedimento de se eleger aleatoriamente um critério qualquer de justiça social para soluções momentistas, conforme alerta Tom Campbell: "Si la justicia se denice como el valor político prioritario, entonces cualquier cosa que se adopte como uma prioridad política es automaticamente consagrada com el título de justicia"3. Por isso, é preciso identificar se a Carta Magna, para distribuição de benefícios e encargos, elegeu como parâmetros da justiça: segundo mérito, contribuição, necessidades, posição do indivíduo ou, ainda, todas essas situações juntas.

Aristóteles escreveu que, "em todas as ciências, assim como em todas as artes, a finalidade é um bem; e o maior de todos os bens encontra-se, sobretudo, naquela entre todas as ciências que é a mais alta; ora, tal ciência é a política e o bem, em política, é a justiça, que dizer, a utilidade coletiva" ${ }^{\prime 4}$. Fica claro que uma organização social tem uma finalidade que é o chamado "bem comum", de modo que a virtude de um homem seria a prática de atos justos, isto é, um dever para com a comunidade. Para a cultura grega:

Considera-se como injusto aquele que viola a lei, aquele que toma mais do que Ihe é devido, como também aquele que viola a igualdade (tomando, no que respeita às coisas más, menos do que sua parte), de sorte que evidentemente o homem justo (a contrário) é, portanto, o que observa a lei e respeita a igualdade.

1 FERREIRA, Aurélio B. de Hollanda. Dicionário Aurélio eletrônico. Versão 3.0. São Paulo: Nova Fronteira, 1999.

Cf. ROSS, Alf. Direito e justiça. Trad. Edson Bini. Bauru: Edipro, 2000. p. 314.

CAMPBELL, Tom. La Justicia: los principales debates contemporáneos. Barcelona: Gedisa, 2002. p. 25.

ARISTÓTELES. Política. Trad. Torrieri Guimarães. São Paulo: Martins Fontes, 2001. p. 99. 
O justo é, portanto, o que é conforme à lei e respeita a igualdade, e o injusto o que é contrário à lei e falta à igualdade. ${ }^{5}$

Na perspectiva de a justiça ser um estado de espírito, Hans Kelsen compreendeu que o grande anseio por justiça pelo homem é uma busca por felicidade, ou seja, "justiça é felicidade social, é a felicidade garantida por uma ordem social" 6 . Essa relação entre justiça e felicidade também pode ser encontrada na doutrina de Platão, sendo que ele conceituava a justiça como a soma das virtudes da moderação, coragem e sabedoria ${ }^{7}$. Enquanto Platão compreendia a justiça de forma absoluta, Aristóteles a concebia de forma relativa, defendia a noção do meio-termo, mediante a proporção, do "dar a cada um o que é seu", definindo-a da seguinte forma:

A justiça é uma espécie de meio-termo, porém não no mesmo sentido que as outras virtudes, e sim porque se relaciona com uma quantia ou quantidade intermediária, enquanto injustiça se relaciona com os extremos. ${ }^{8}$

Neste caso, se justiça é felicidade, "então uma ordem social justa é impossível, enquanto justiça significar felicidade individual" ${ }^{\prime}$. Entende Kelsen que felicidade é um valor muito subjetivo, na medida em que cada indivíduo teria um conceito próprio, muitas vezes conflitante com o dos outros indivíduos. Imagine-se a situação hipotética de dois homens disputando um cargo público ou o amor de uma mulher; somente um alcançará o objetivo e, consequentemente, somente um alcançará a felicidade, até porque a realidade social proporcionará a cada indivíduo resultados diferentes.

Isso deixa claro que a própria natureza do homem possui inclinações e instintos, ou seja, o homem age por impulsos e paixões que se afastam da razão, o que acabará por influenciar os critérios que cada um tem a respeito da justiça. A concepção do positivismo jurídico, desenvolvida por Hans Kelsen, seria transformar o Direito numa ciência autônoma, sistemática e unitária, aplicando um rigor metodológico, isto é, um sistema de pureza na análise dos institutos jurídicos (Teoria Pura do Direito). Antônio Carlos de Almeida Diniz explica que "a principal característica no marco do direito positivo moderno é a conversão operada da legitimidade em legalidade". Nessa perspectiva, "a legalidade seria assim, segundo a exigência lógica da racionalidade, o modelo moderno de legitimidade ${ }^{\prime 10}$. Com isso, pode-se compreender que a legitimidade do Estado

5 Industrial S.A., 1973. p. 216.

6 KELSEN, Hans, O que é justiça? A justiça, o direito e a política no espelho da ciência. Trad. Luís Carlos Borges. 3. ed. São Paulo: Martins Fontes, 2001. p. 2.

PLATÃO. A república. Trad. Enrico Corvisieri. São Paulo: Nova Cultural, 1992.

ARISTÓTELES. Op. cit., p. 1095b.

KELSEN, Hans. Op. cit., p. 3.

0 GOYARD-FABRE, Simone. Citada por DINIZ, Antonio Carlos de Almeida. Teoria da legitimidade do direito e do estado: uma abordagem moderna e pós-moderna. São Paulo: Landy, 2006. p. 94. 
estaria associada à ideia de que os limites do poder estariam estabelecidos em "lei".

A justiça sempre foi trabalhada numa perspectiva de função do Estado, tendo como função a defesa do bem comum da sociedade. Por isso, torna-se necessário perquirir quais as bases ideológicas que mais influenciaram a construção do atual Estado Democrático de Direito brasileiro.

Primeiramente, ao se estudar a respeito do desenvolvimento do Estado, é necessário se compreender que ele não é um resultado, mas sim um processo que passou por várias mudanças paradigmáticas ${ }^{11}$, ou seja, os modelos aceitos passaram a ser retrabalhados de maneira a permitir a formação de uma nova forma estatal que melhor atendesse a sociedade naquele dado momento histórico. Em muitas situações, um novo paradigma pode ser desenvolvido por meio de uma ruptura com o sistema anterior, mas, em outros casos, também é possível que ocorra uma releitura das funções estatais, sem, no entanto, abandonar as premissas anteriores.

A partir de um recorte histórico, é possível notar que, durante o período medieval, o poder existente se concentrava em um sistema político fundado essencialmente em vínculos pessoais, onde entre os senhores feudais e seus vassalos funcionava uma espécie de superioridade territorial como força legitimadora. Comenta Jorge Miranda que o período medieval é marcado por um ordenamento jurídico sob o regime patriarcal, colocando o príncipe, e não a cidade, como centro da vida política, o que possibilitou a existência de privilégios concedidos com base na vontade pessoal do governante:

E porque não há uma relação geral e imediata entre o poder do Rei e os súbditos, os direitos são a estes conferidos não enquanto tais, individualmente considerados, mas sim enquanto membros dos grupos em que se integram; são direitos em concreto e em particular, como expressão da situação de cada pessoa; direitos que se apresentam como privilégios, regalias, imunidades que uns têm e outros não, ou direitos institucionais, em vez de direitos atribuídos genericamente a todas as pessoas. ${ }^{12}$

A vontade do príncipe era a própria fonte da lei; predominava o entendimento de que o poder imperial possuía fundamentação divina, como uma espécie de transferência de legitimidade em proveito do príncipe, de modo que sua vontade se tornaria inquestionável pelos súditos.

Na época medieval, a população se mostrou extremamente impotente aos desmandos estatais e subordinada ao voluntarismo do governante absolu-

11 Para Thomas Kuhn, a noção de paradigma passa a ideia de mudança, ou seja, uma revolução cientifica ocorre quando um novo paradigma vem a substituir um anterior, sendo que a cada revolução ocorre este novo ciclo e um novo paradigma é instalado. Podem existir varias razões para uma mudança paradigmática, podendo ser que o novo modelo responda com mais eficiência do que o anterior os problemas atuais (Cf. KUHN, Thomas. A estrutura das revoluções científicas. São Paulo: Perspectiva, 2000. p. 43).

12 MIRANDA, Jorge. Teoria do Estado e da Constituição. Rio de Janeiro: Forense, 2007. p. 31. 
tista, demonstrando o surgimento de insatisfações populares. A sociedade medieval se abre a questionamentos de cunho filosófico-religioso, reconhecendo a individualidade do ser humano e identificando uma possível falta de legitimidade no poder do príncipe ${ }^{13}$.

O anseio popular em busca de um sistema de proteção individual e de segurança foi crescendo com o tempo, abandonando continuamente o modelo que funcionava até então, no qual o poder estatal não encontrava limites efetivos ao seu exercício. A decadência do modelo feudal foi um fato determinante para a formação do Estado moderno, mediante a afirmação dos elementos da territorialidade, soberania e o povo ${ }^{14}$. E cada vez mais os laços pessoais nas relações dos poderes estatais foram progressivamente sendo substituídos por uma espécie de hierarquia-administrativa em torno da soberania do Estado, o que, por consequência, estabelecia também em nível progressivo um rol de direitos e deveres dos indivíduos ${ }^{15}$.

A limitação e a racionalização do poder estatal somente surgem com a inauguração do "Estado de Direito", desenvolvido no fim do século XVIII e início do XIX, tradicionalmente atribuída às revoluções americana e francesa, que vem a consolidar as doutrinas liberais. O pensamento burguês liberal traz como discurso a necessidade de o Estado reconhecer os direitos individuais, mediante a proteção de cada indivíduo da intervenção do Estado. Esse momento caracterizou uma importante conciliação, ou até mesmo uma reconciliação, entre a ordem política e a liberdade das pessoas ${ }^{16}$.

A partir da concepção liberal do Estado de Direito, verifica-se uma conquista significativa no campo dos direitos individuais, provocando uma série de alterações da relação existente entre o Estado e a sociedade civil, isto é, foi neste momento que houve a conversão de súditos em cidadãos livres ${ }^{17}$.

O movimento revolucionário francês simbolizou a quebra dos laços de submissão do povo (burguesia) aos desmandos do absolutismo, representando, a partir deste momento, a emancipação política e social da nação ${ }^{18}$. Por meio de um conjunto amplo de reformas antiaristocráticas em defesa pela liberdade veio a ampliar a participação política, fazendo do Estado liberal um cenário ideal para o ressurgimento do espaço público, sem comprometer o espaço privado. Se de um lado o Estado teria o monopólio do uso legítimo da força e legitimidade para o exercício do poder de tributar (criar tributos), do outro o

13 Cf. NAY, Olivier. História das ideias políticas. Trad. Jaime A. Clasen. Petrópolis: Vozes, 2007. p. 117 ss.

14 Cf. DALLARI, Dalmo de Abreu. Elementos de teoria geral do Estado. São Paulo: Saraiva, 2003. p. 71.

15 Cf. CHÂTELET, François; DUHAMEL, Oliver; PISIER-KOUCHNER, Evelyne. História das idéias políticas. Trad. Carlos Nelson Coutinho. Rio de Janeiro: Jorge Zahar, 2000. p. 34.

16 Cf. GOYARD-FABRE, Simone. Os princípios filosóficos do Direito político moderno. São Paulo: Martins Fontes, 2002. p. 309.

17 Cf. MIRANDA, Jorge. Op. cit., p. 45.

18 Cf. BONAVIDES, Paulo. Teoria do Estado. 4. ed. São Paulo: Malheiros, 2003. p. 28. 
cidadão teria direitos individuais assegurados para ser utilizados como proteção em face do ente estatal ${ }^{19}$.

O que se pode afirmar é que o liberalismo significou a limitação do poder da autoridade pública, e por isso que Norberto Bobbio vem a definir o liberalismo como "uma doutrina do Estado limitado tanto com respeito a seus poderes quanto às suas funções" 20 , de modo que toda a intervenção estatal que extrapolasse a função abstencionista de proteção da liberdade individual seria considerada ilegítima, pois enfraqueceria a autonomia dos indivíduos. Com isso, a ascensão da classe burguesa fez com que houvesse a construção de um Estado fraco (Estado mínimo), com funções restringidas à vigilância da ordem social, ou seja, inaugura-se um modelo em que o poder estatal se transformou em instrumento de defesa da liberdade individual, através da utilização de meios despidos de substancialidade para garantir a autonomia privada dos indivíduos ${ }^{21}$.

Isso vem a modelar um sistema em que o poder estatal estará obrigado a garantir a liberdade individual, mas de forma a não comprometer a autonomia privada dos cidadãos. O momento inicial do movimento liberal ficou significativamente marcado pela posição estatal abstencionista, de modo que "convinha rodear-Ihe de freios constitucionais a ação invasora, duramente sentida durante as épocas do absolutismo, mitigando-se-lhe assim a força coercitiva" ${ }^{\prime 22}$. Com isso, promoveu-se a substituição do Estado forte do leviatã pelo Estado fraco liberal, uma vez que o império da lei veio a criar obstáculos jurídicos contra a tirania dos governantes.

A influência do liberalismo fez a proteção estatal estar essencialmente voltada para a liberdade individual em detrimento de uma visão dos interesses da comunidade, colocando o cidadão como responsável por seus atos e construtor dos valores morais da sociedade. O foco de atenção estaria sobre o indivíduo, de modo que não caberia ao Estado atrapalhar esse processo de desenvolvimento individual, defendendo-se que a presença estatal deveria ser a mais neutra possível, em atenção à regra de, "quanto menos palpável a presença do Estado nos atos da vida humana, mais larga e generosa a esfera de liberdade outorgada ao indivíduo. Caberia a este fazer ou deixar de fazer o que the aprouvesse" ${ }^{\prime 23}$, dando força à famosa ideologia liberal do laissez-faire, laissez-passer. Isso vem a estabelecer que o papel do Estado liberal era de apenas manter a segurança jurídica e a liberdade de iniciativa, de modo que o indivíduo possa por suas próprias qualidades atingir a sua potencialidade.

19 Cf. BARROSO, Luis Roberto. Curso de Direito Constitucional contemporâneo. São Paulo: Saraiva, 2009. p. 64.

20 BOBBIO, Norberto. Liberalismo e democracia. São Paulo: Brasiliense, 1988. p. 17.

21 Cf. CHÂTELET, François; DUHAMEL, Oliver; PISIER-KOUCHNER, Evelyne. Op. cit., p. 107.

22 BONAVIDES, Paulo. Op. cit., p. 87.

23 BONAVIDES, Paulo. Do Estado Liberal ao Estado Social. 7. ed. São Paulo: Malheiros, 2001. p. 60. 
Assim, o Estado de Direito, alinhado às Revoluções Americana (1776) e Francesa (1789), concebeu a legalidade sob o aspecto de liberdade negativa, onde a sua principal função centra-se em atuar como garantidora das liberdades formais das pessoas frentes aos abusos do Estado. Como consequência, a conduta seria entendida como justa na medida em que ela esteja enquadrada nos parâmetros da lei, havendo um critério de validade objetivo. Isso desencadeou um posicionamento em que, segundo Robert Nozick, os direitos individuais poderiam ser interpretados como restrições de ação e não como um estado final a ser realizado ${ }^{24}$. Para este autor, os direitos não determinam um ordenamento social, mas apenas criam uma situação para que as escolhas sociais possam ser feitas. Caso contrário, o Estado estaria tratando as pessoas como meios para alcançar seus próprios fins, não respeitando sua inviolabilidade pessoal.

Com isso, o pensamento liberal vem a defender que as constrições morais devem ser respeitadas de forma absoluta, a fim de se evitar que as decisões individuais sejam condicionadas ou sofram qualquer tipo de intervenção. Em uma sociedade liberal, o que deverá prevalecer são os interesses individuais, de modo que cada qual crie condições para atingir sua concepção de boa vida, desde que para isso não cause danos para outrem. Nesse mesmo sentido, Friedrich August Von Hayek defende que a liberdade somente existirá quando o homem for livre em esperar o imprevisível, condição oportuna para realizar seus objetivos ${ }^{25}$. Em outras palavras, para este autor, a liberdade individual pode ser entendida como o estado no qual o indivíduo não esteja sujeito ao arbítrio de outrem, isto é, a ausência de coerção, de modo que se evite a situações como aquelas em que "o coagido ainda possa escolher, as alternativas são-lhe impostas pelo coator de modo que ele escolha o que este pretende. Ele não é totalmente privado do uso de suas faculdades mentais, mas é privado da possibilidade de utilizar seus conhecimentos para alcançar seus próprios objetivos" 26 . Ser livre então seria a concepção de ter a liberdade de fazer escolhas, o direito de errar e acertar, livremente, sozinho, sem interferências, desde que tenha plena ciência de que deverá arcar com as consequências de suas ações ${ }^{27}$.

Explica Álvaro Vitta que existem os deveres negativos e positivos; os primeiros são aqueles conhecidos como constrições morais, e os segundos referem-se aos auxílios a outras pessoas necessitadas. Para o liberalismo clássico, somente os primeiros são deveres no sentido forte, sendo que os deveres positivos deveriam ser pautados no critério meritório ${ }^{28}$. Assim, o desenvolvimento dos indivíduos se escalona conforme a capacitação de cada um para atingir os

24 NOZICK, Robert apud VITA, Álvaro. A justiça igualitária e seus críticos. São Paulo: Martins Fontes, 2007. p. 35.

25 Cf. HAYEK, Friedrich August Von. Os fundamentos da liberdade. Brasília: UnB, São Paulo: Visão, 1983. p. 9.

26 HAYEK, Friedrich August Von. Op. cit., p. 146

27 Para Hayek, a liberdade é inseparável da responsabilidade. "A liberdade não apenas significa que o indivíduo tem a oportunidade de e, ao mesmo tempo, a responsabilidade de escolher; também significa que deve arcar com as consequências de suas ações" (HAYEK, Friedrich August Von. Op. cit., p. 76).

28 Cf. VITA, Álvaro. Op. cit., p. 50. 
melhores níveis e os benefícios somente seriam justificados caso houvesse uma contrapartida anterior pelo indivíduo beneficiário, de modo que as instituições de um Estado liberal não podem se fundamentar em julgamentos de valores dos quais as pessoas individualmente não se empenharam para alcançar. Nesta concepção, o Estado apenas tem a finalidade de manter um ambiente propício para que cada indivíduo, dentro da sociedade, possa ter condições de desenvolver seus talentos e receber os benefícios. Assim, o poder público deverá proteger o princípio da igualdade, mas o que não pode haver é o estabelecimento de normas que pretendam impô-la aos indivíduos ${ }^{29}$, o que deveria se evitar que as pessoas contra sua vontade estejam obrigadas por normas igualitárias.

Baseado em um discurso pela segurança jurídica, a corrente positivista do direito ganha força na medida em que vai se tornando exclusiva fonte de Direito, isto é, a progressiva expansão da positivação do direito desencadeou a figura do Estado de Direito como um Estado da legalidade. Isso, historicamente, foi uma reação em face do Estado de Polícia, o qual não havia limites preestabelecidos; estava apenas no alvitro do governante ${ }^{30}$.

Ao contrário do direito natural, que estudava a justiça como um caráter absoluto e ideal, e assim a colocava como critério de validade da ordem jurídi$\mathrm{Ca}^{31}$, o positivismo jurídico estudava os conflitos sociais sob o enfoque objetivo. Frente a esse entendimento, Kelsen propõe este instigante embate, entendendo haver um dualismo entre justiça e direito, de um lado "uma ordem transdente, ideal, que não é estabelecida pelo homem mas Ihe está supraordenada, e uma ordem real estabelecida pelo homem, isto é, positiva" ${ }^{\prime 32}$. Segundo essa concepção, a validade do direito positivo é independente da validade da norma de justiça, sendo que o direito positivo não é considerado válido pelo fato de ser justo; até pelo contrário, pode ser válido ainda que injusto ${ }^{33}$.

Atente-se que Kelsen não defende que não haja nenhuma justiça. Ao contrário, pressupõe a existência de várias normas de justiça, diferentes umas das outras e possivelmente contraditórias entre si. Ainda que se permita uma análise do Direito sob critério de justiça, ela jamais poderá servir de critério de validade, por possuir um caráter relativo ${ }^{34}$, sendo que "as normas que são efetivamente usadas como padrões de justiça variam de indivíduo para indivíduo

29 Cf. GARGARELLA, Roberto. As teorias da justiça depois de Rawls: um breve manual de filosofia política. São Paulo: Martins Fontes, 2008. p. 44.

30 Cf. ZAGREBELSKI, Gustavo. El derecho dúctil. Madrid: Trotta, 1995. p. 21

31 "O Direito deduzido da natureza é um direito eterno e imutável, em contraposição ao Direito positivo, que, criado pelo homem, é apenas uma ordem temporária e mutável; que os direitos estabelecidos pelo direito natural são direitos sagrados inatos ao homem porque implantados no homem por uma natureza divina. E que o Direito positivo não pode estabelecer nem abolir esses direitos." (KELSEN, Hans. O que é justiça? A justiça, o direito e a política no espelho da ciência. Trad. Luís Carlos Borges. 3. ed. São Paulo: Martins Fontes, 2001. p. 138/139)

32 KELSEN, Hans. Op. cit., p. 68.

33 KELSEN, Hans. Op. cit., p. 68.

34 "O direito natural, trazido em confronto com o direito positivo, poderia na verdade servir de medida ou critério de apreciação para o efeito de decidir-se se este direito é justo ou injusto, mas não poderia pôr em questão a 
e muitas vezes são mutuamente irreconciliáveis [...]. Os juízos de justiça não podem ser posto à prova objetivamente. Portanto, na ciência do Direito, não tem espaço para eles" ${ }^{\prime \prime 3}$.

Ocorre que a legalidade construída no Estado liberal vinha perdendo cada vez mais referência para com o seu objetivo de proteção dos direitos individuais. A insuficiência desse sistema como protetor dos cidadãos foi se agravando até o ponto de ser manipulado por governos, que utilizaram a força legitimadora deste modelo para construção de esquemas formais de governo. Exemplos clássicos podem ser observados nos Estados totalitários da Europa ocidental, onde os poderes marcadamente antiliberais foram desenvolvidos na edificação do Estado com o fim em si próprio. Com a utilização do aparato (instrumentos) do Estado de Direito construído até aquele momento, o Estado fascista italiano e o nacional-socialismo na Alemanha promoveram a centralização do poder sem que houvesse uma quebra da "legitimidade legal".

Todo esse panorama histórico leva Jorge Reis Novais a concluir que, embora o primado da lei e a segurança jurídica sejam mecanismos de contenção do poder, sozinhos não podem ser considerados como garantias dirigidas a garantir os direitos fundamentais ${ }^{36}$. Ao mesmo tempo, o Judiciário foi concebido com a função puramente negativa, sem possibilidade de interferências positiva no campo dos direitos fundamentais, sob pena de ofensa à separação dos poderes. Essa situação histórica é compreendida a partir das razões que motivaram a Revolução Francesa, bem como da constatação de que os juízes eram oriundos de classes aristocráticas, o que acabou por gerar uma extrema desconfiança em relação a eles, pois havia o receio de que um poder não popular tivesse a possibilidade de modificar uma lei elaborada pela vontade do povo ${ }^{37}$.

Frente a essa crise do modelo liberal, foi possível perceber a necessária criação de um Estado solidário. Em outras palavras, Jorge Reis Novaes leciona que: "[...] ao lado dos direitos e liberdades clássicos - moldados e comprimidos, particularmente no que se refere ao direito de propriedade, à medida das novas exigências de socialidade - avultam, agora, os chamados direitos sociais indissociáveis das correspondentes prestações do Estado" ${ }^{\prime 3}$. Assume o Estado o encargo de buscar uma reconfiguração de sua atuação na sociedade, atendendo a necessidades até então a responsabilidade da autonomia privada, concebia-se, neste momento, o modelo do Estado do bem-estar social.

sua validade." (KELSEN, Hans. O problema da justiça? A justiça, o direito e a política no espelho da ciência..., p. 113)

35 KELSEN, Hans. O que é justiça? A justiça, o direito e a política no espelho da ciência..., p. 222/223.

36 NOVAIS, Jorge Reis. Contributo para uma teoria do Estado de direito: do estado de direito liberal ao Estado social e democrático de direito..., p. 126.

37 Cf. MENDES, Gilmar Ferreira; COELHO, Inocêncio Mártines; BRANCO, Paulo Gustavo Gonet. Curso de direito constitucional. 4. ed. São Paulo: Saraiva, 2009. p. 223.

38 NOVAIS, Jorge Reis. Contributo para uma teoria do Estado de direito: do estado de direito liberal ao Estado social e democrático de direito..., p. 197. 
As experiências vividas na Primeira Guerra Mundial, juntamente com outros fatos, fez com que se repensasse acerca do papel do Estado na sociedade, a fim de se mudar novamente o seu fundamento paradigmático, pois, se ao mesmo tempo em que o Estado reconhecia o direito do indivíduo ser livre, não se assegurava a ninguém o poder de ser livre ${ }^{39}$. Em outras palavras, se com a inauguração do Estado liberal, o indivíduo obteve o reconhecimento de direitos, ao mesmo tempo se percebeu que a garantia de tais direitos ficou apenas no plano formal, não havendo uma significativa melhoria de condição das pessoas em geral em relação com a situação anterior. Para Menelick de Carvalho Netto, é a partir desse descontentamento popular gerado durante a égide da concepção liberal que surgem questionamentos, principalmente com base em ideias socialistas, comunistas e anarquistas, que, de forma crescente, animaram "os movimentos coletivos de massa cada vez mais significativos e neles reforça com a luta pelos direitos coletivos e sociais" ${ }^{\prime \prime 4}$.

Diante das consequências geradas pelo descontentamento popular é que se identifica a crise do modelo liberal, gerando um esgotamento do modelo vigente. Com o aumento das demandas sociais, principalmente com o fim da Primeira Guerra Mundial, demonstrou que a sociedade dependeria de uma posição atuante (intervencionista) do Estado para a concretização dos direitos formalmente reconhecidos. Isso fez o Estado tomar uma nova postura, gerando uma série das mudanças, como a flexibilização do sistema formal em prol do desenvolvimento de um Estado do bem estar social, o qual, por sua vez, vem a garantir direitos mínimos do cidadão, como a renda mínima, assistência social, saúde, moradia, etc. Esses direitos não seriam mais entendidos como caridade, mas, agora, como direitos políticos mínimos, que estariam englobados na "condição instrumento do Estado, compromisso com o bem comum e com a dignidade do ser humano, consolidando-se concretamente, conforme as condições expostas em cada sociedade e Estado, e tendo como conteúdo finalístico a ideia de justiça social" ${ }^{\prime \prime 1}$.

De forma inovadora no aspecto jurídico, a Constituição mexicana de 1917 e a de Weimar de 1919 são consideradas como o marco do constitucionalismo social, representando a crise do Estado liberal e a materialização dos ideais do Estado social. Foi por meio dos ideais do constitucionalismo social que se percebeu efetivamente a necessidade de o Estado proteger não somente os direitos e liberdades individuais, que teve seu reconhecimento conquistado nas revoluções liberais, mas também de se preservar e fomentar o desenvolvimento social dos indivíduos, passando a ser vistos como membros de uma sociedade, e não somente como seres individuais e autônomos.

39 Cf. DALLARI, Dalmo de Abreu. Elementos de teoria geral do Estado..., p. 277.

40 CARVALHO NETTO, Menelick de. Requisitos paradigmáticos da interpretação jurídica sob o paradigma do Estado democrático de direito. Revista de Direito Comparado, Belo Horizonte, n. 3, p. 478, maio 1999.

41 STRECK, Lenio Luiz; MORAIS, José Luis Bolzan de. Ciência política e teoria geral do Estado..., p. 72. 
A dignidade da pessoa humana foi colocada como pilar de sustentação do Estado, a fim de que a ideia de direitos sociais repercuta numa espécie de "processo conjunto de estadualização da sociedade e socialização do Estado que se corporiza o princípio de socialidade enformador do novo Estado social e, por sua vez, é essa dupla dimensão que permite distinguir o Estado social dos conceitos afins" ${ }^{\prime \prime 2}$. O grande diferencial do Estado social é que, por sua própria natureza, é estabelecido um Estado interventor, que exige um poder político extremamente atuante na esfera social, onde se identifica uma dependência da sociedade em receber serviços públicos ${ }^{43}$.

Luigi Ferrajoli identifica que, até a Segunda Guerra Mundial, a teoria jurídica que predominava era ainda a legalidade, em que a legitimidade das ações estatais estaria fundada, exclusivamente, por previsões postas por autoridade competente, independente de discussões se tais condutas seriam justas ou não. Com o término da guerra, houve um movimento denominado de neoconstitucionalismo, que produziu um abandono do mero papel descritivo das realizações do processo de constitucionalização, passando a valorá-los positivamente a busca de sua ampliação. Assim, o controle da validade de uma lei que outrora estava dissociado da noção de justiça agora passa a será avaliada substancialmente sob o contraste de valores consagrados pela Constituição ${ }^{44}$. Por se tratar de um fenômeno ainda não consolidado, ou seja, que ainda está acontecendo, não é possível descrever todos os seus contornos. Mesmo assim, a doutrina costuma estudar alguns efeitos gerados pelo neoconstitucionalismo, agregando-o à noção de Estado Democrático de Direito, o que tem gerado uma notável evolução na releitura dos institutos jurídicos anteriormente criados ${ }^{45}$.

Nesta mesma direção, Luis Pietro Sanchis leciona que o neoconstitucionalismo implicou um fortalecimento na ordem constitucional, mediante a superação do Direito ordinário. Esse fortalecimento ficou evidenciado pela busca da construção de um modelo de direito constitucional além do positivismo, pois as mudanças ocorridas no meio jurídico e econômico fizeram haver a necessidade de uma nova filosofia do Direito ${ }^{46}$. Seria uma tentativa na efetiva transformação do Estado legislativo de Direito para o Estado constitucional de Direito, promovendo a reintrodução das ideias de justiça e legitimidade na aplicação jurídica. A consolidação do constitucionalismo democrático provocou um significativo impacto na figura do Estado perante a sociedade, o que propiciou que houvesse valiosas reflexões quanto ao verdadeiro papel do Direito na sociedade atual, a

42 NOVAIS, Jorge Reis. Contributo para uma teoria do Estado de direito: do estado de direito liberal ao Estado social e democrático de direito..., p. 197/198.

43 Cf. BONAVIDES, Paulo. Do estado liberal ao estado social..., p. 200.

44 Cf. FERRAJOLI, Luigi. Pasado y futuro del estado de derecho. In: CARBONELL, Miguel (Org.). Neoconstitucionalismo(s)..., p. 16 e ss.

45 Cf. COMANDUCCI, Paolo. Formas de (neo)constitucionalismo: um análisis metateórico. In: CARBONELL, Miguel (Org.). Neoconstitucionalismo(s). Madrid: Trotta, 2003. p. 90.

46 Cf. SANCHÍS, Luis Prieto. Constitucionalismo y positivismo. México: Distribuciones Fontamara, 1999. p. 16. 
recepção de valores sociais na interpretação constitucional, a promoção dos direitos fundamentais, etc. ${ }^{47}$

Em linhas gerais, o neoconstitucionalismo pode ser entendido como essa nova postura dos intérpretes perante o Direito, em que, além de manter limites e induzir o Estado a promover ações positivas, também tem transformado o saber jurídico em uma ciência mais crítica a respeito da atuação do Poder Público.

O Estado Democrático de Direito, desenvolvido com base neste fenômeno jurídico, tem melhores condições de promover a eliminação da rigidez formal em prol do atendimento à supremacia da vontade do povo e a implementação da igualdade substancial na sociedade. Com isso, o Estado passa a ter como pressupostos uma "organização flexível, que assegure a permanente supremacia da vontade popular, buscando-se a preservação da igualdade de possibilidades, com liberdade, a democracia deixa de ser um ideal utópico para se converter na expressão concreta de uma ordem social justa"48. Em outras palavras, pode-se compreender que as terminologias "Democrático e Estado de Direito", neste estágio do constitucionalismo moderno, são entendidos como qualidades indissociáveis do Estado constitucional, isto é, se de um lado há uma legitimidade do direito e do processo legislativo, do outro há um círculo de legitimidade do poder político ${ }^{49}$.

\section{II - A INFLUÊNCIA DA TEORIA DA JUSTIÇA COMO EQUIDADE DE JOHN RAWLS}

Esta legalidade formal perdia cada vez mais referência, pois a neutralidade utilizada pelo Estado de legalidade foi cada vez mais utilizada como instrumento de manipulação popular, situação essa que colocava as pessoas como instrumentos do Estado. Isso se agravou ainda mais com o contundente avanço dos efeitos da globalização capitalizada, criando uma forte cultura consumerista em que, segundo Tarso Genro, o "sentimento de pertencimento a uma comunidade determinada seja nacional ou local é substituído pelo sentimento de rebanho, voltado para o consumo e o prazer alienado" ${ }^{\prime 50}$. Frente a essa crise do modelo liberal, foi possível perceber a necessária criação de um Estado solidário. Assume o Estado o encargo de buscar uma reconfiguração de sua atuação na sociedade, atendendo a necessidades até então a responsabilidade da autonomia privada, concebia-se, neste momento, o modelo do Estado do bem estar social.

Dentro desse cenário político, John Rawls propõe uma estratégia contratualista em que vem a defender que não é suficiente as sociedades serem

\footnotetext{
Cf. BARROSO, Luis Roberto. Curso de direito constitucional contemporâneo..., p. 262 e ss.

Cf. DALLARI, Dalmo de Abreu. Elementos de teoria geral do Estado. São Paulo: Saraiva, 2003. p. 307.

Cf. CANOTILHO, Jose Joaquim Gomes. Direito constitucional e Teoria da Constituição..., p. 100.

GENRO, Tarso. Citado por SALGADO, Eneida Deiree. Constituição e democracia. Tijolo por tijolo em um desenho (quase) lógico: vinte anos de construção do projeto democrático brasileiro. Belo Horizonte: Fórum, p. 69.
} 
apenas organizadas e eficientes, mas devem, além disso, serem justas. Com base nesse enunciado é que Rawls irá propor uma teoria de justiça, acreditando ser a melhor maneira de as instituições públicas atuarem perante os cidadãos e, consequentemente, existirem sociedades justas e boas de se viver ${ }^{51}$.

Para este autor, conhecido como defensor da corrente igualitarista, a justiça de uma sociedade depende de como se regulamentarão os direitos, as obrigações, as oportunidades econômicas e as condições sociais ${ }^{52}$. Por isso ele foge da definição de um conceito metafísico da justiça, mas procura definir um conceito político, sendo o resultado de uma pluralidade de concepções de justiça. O que se tentou foi quebrar com as soluções utilitaristas, ou seja, aquelas decisões que são tomadas por serem cômodas e, por agradarem a maioria de pessoas, muitas das vezes tomadas quando não se sabe qual seria a resposta correta $^{53}$.

A ideia passada pelo utilitarismo era de que a sociedade estaria ordenada de modo que as instituições estão planejadas a atender o maior número possível de satisfações pessoais. Essa situação acaba por considerar como iguais as diferentes preferências em jogo em determinado embate de interesses, o que acaba criando uma situação totalmente injusta: sacrificar algum grupo em prol da melhoria de vida dos demais. Assim, o bem-estar da sociedade estaria baseado na satisfação da maioria dos indivíduos, de modo que não se levava em conta a promoção do bem-estar do invidíduo isoladamente, não se considerava seu plano de vida. Ao momento em que o princípio da utilidade apenas buscava maximizar a soma algébrica das vantagens em uma determinada sociedade, ela se tornaria incompatível com a cooperação social ${ }^{54}$.

A teoria da justiça ora defendida visa alterar a estrutura básica da sociedade, modificando o modo como é despedido o tratamento das instituições sociais no momento da distribuição de direitos e deveres. Uma forma em que o homem seja reconhecido como autônomo, tendo respeitados seus direitos de escolha de forma individual. Assim Rawls propõe um modelo de "justiça procedimental pura", através da qual "seria considerada justiça processual perfeita se existisse tanto uma ideia independente e clara do que é um resultado justo, como um processo capaz de garantir esse resultado" ${ }^{\prime 55}$. Através de um processo de escolha imparcial, diz o autor, que se poderia criar um sistema de "justiça como equidade".

Neste sistema, haveria uma situação hipotética em que o homem deverá fazer a escolha dos princípios morais, não devendo estar subordinado a situa-

51 Cf. KUKATHAS, Chandran; PETTIT, Philip. Raw/s: uma teoria da justiça e seus críticos..., p. 71.

52 Cf. RAWLS, John. Uma teoria da justiça. Trad. Almiro Pisetta e Lenita M. R. Esteves. São Paulo: Martins Fontes, 1997. p. 8.

53 Cf. RAWLS, John. Uma teoria da justiça..., p. 4.

54 Cf. RAWLS, John. Uma teoria da justiça..., p. 16.

55 GARGARELLA, Roberto. As teorias da justiça depois de Raw/s: um breve manual de filosofia política..., p. 20. 
ções particulares, o que seria evitado, segundo Rawls, pelo fato de que os indivíduos racionais e interessados em si próprios iriam deliberar sobre princípios que iriam servir de base para a convivência social ${ }^{56}$. Estariam esses indivíduos, sob uma espécie de "véu da ignorância", em que cada qual, sem conhecer qual seria sua classe, raça, sua concepção de bem, iria propor concepções gerais para estrutura básica social. Estariam os indivíduos direcionados a buscar um acordo imparcial sobre as decisões de todos os participantes. A partir dessa concepção, "os princípios da justiça são escolhidos sob um véu de ignorância. Isso garante que ninguém é favorecido ou desfavorecido na escolha dos princípios pelo resultado do acaso natural ou pela contingência de circunstâncias sociais" ${ }^{\prime \prime 5}$.

Em síntese, seria estabelecido inicialmente um esquema procedimental, em que numa posição original e abaixo de um véu da ignorância seriam definidos os princípios da justiça que serviriam de diretriz para a atuação e para as escolhas dos cidadãos dentro de seus planos particulares de vida. Essa estrutura procedimental, segundo Rawls, irá garantir uma justiça substancial, promovendo uma estrutura social básica estável.

Ainda que John Rawls acreditasse haver dificuldade em se obter juízos imparciais na escolha inicial dos princípios da justiça, defende este autor que seria possível obter deliberações razoáveis e racionalmente aceitáveis, sob o argumento de que o ser humano é uma criatura que tem a noção de seu bem e capaz de ter noção de justiça. Ora, há situações, como intolerância religiosa e discriminação racial, que são consideradas injustas, por um critério imparcialmente aceito, o que demonstra a existência de uma coincidência de convicções entre os indivíduos ${ }^{58}$. Com isso, a dependência por particularidades ou intencionismos tende a ser minorada na medida em que se colocam questões mais definidas, de modo a atingir um consenso confiável no modo de julgar, a fim de estabelecer uma noção coletiva de justiça $\mathrm{a}^{59}$.

Após a escolha da concepção de justiça (aceitabilidade), haverá um passo seguinte em que as pessoas irão formular uma constituição e assim por diante em consonância com os princípios da justiça incialmente pactuados ${ }^{60}$. Esse esquema equitativo de cooperação social será desenvolvido com a finalidade de efetivar os direitos da liberdade e igualdade, de modo que a preocupação da teoria da justiça em Rawls é de que todos devem ter condições de buscar seu próprio plano de vida, independente do que se escolha fazer.

56 Cf. GARGARELLA, Roberto. As teorias da justiça depois de Rawls: um breve manual de filosofia política..., p. 21.

57 RAWLS, John. Uma teoria da justiça..., p. 13.

58 Cf. RAWLS, John. Uma teoria da justiça..., p. 22.

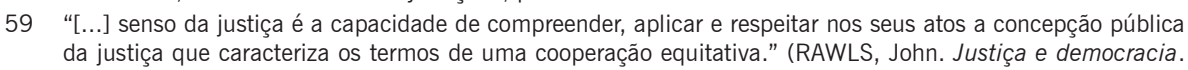
Trad. Irene Paternot. São Paulo: Martins Fontes, 2000. p. 216)

60 Cf. RAWLS, John. Uma teoria da justiça..., p. 14. 
Como defensor do liberalismo igualitário, este autor americano entende que as desigualdades sociais atingem as possibilidades de vida dos seres humanos. É sobre tais desigualdades que a concepção da justiça deve ser aplicada, através da busca por uma equidade, sendo que a teoria de Rawls possui dois postulados condutores: "Todas as pessoas têm igual direito a um projeto inteiramente satisfatório de direitos e liberdades básicas para todos, projeto este compatível com todos os demais; e, nesse projeto, as liberdades políticas, e somente estas, deverão ter seu valor equitativo garantido". E também defende que "as desigualdades sociais e econômicas devem satisfazer dois requisitos; (a) devem estar vinculadas a posições e cargos abertos a todos, em condições de igualdade equitativa de oportunidades; e (b) devem representar o maior benefício possível aos membros menos privilegiados da sociedade" ${ }^{\prime 61}$. Em outras palavras, deve-se haver uma garantia de igual liberdade na sociedade quanto ao exercício dos direitos civis. Diante da impossibilidade da concretização deste primeiro postulado, justifica-se a aplicação do segundo, esse de natureza distributiva, que autorizará uma maximização dos benefícios para os desfavorecidos, ou seja, aumentar as oportunidades para quem não as têm ${ }^{62}$.

Na perspectiva de insuficiência na aplicação de liberdades civis, o segundo enunciado de Rawls vai ao sentido de se justificar a existência de uma justiça distributiva através da garantia de igualdade de oportunidades a todos e tratamento diferenciado aos menos favorecidos. Para Roberto Gargarella, na Teoria da Justiça de Rawls, "as violações de uma ideia estrita de igualdade só são aceitáveis no caso de servirem para incrementar as parcelas de recursos em mãos dos menos favorecidos, e nunca de as diminuir" ${ }^{\prime 63}$. Essa atuação não estará embasada no sentido de que as privações de alguns compensará na medida de benefícios de outros, mas haverá, sim, aplicação justa quando os benefícios maiores sejam destinados à melhoria dos marginalizados, buscando alcançar a equidade. A ideia deste sistema é de que o bem-estar de todos depende de um sistema de cooperação, sem a qual não haveria possibilidade de atingir um bem comum na sociedade ${ }^{64}$.

Nesse sentido, pode-se identificar uma contraposição entre a corrente liberal, enganjada por Rozick e Hayek, e a corrente liberal igualitária, tendo por maior expoente John Rawls. A primeira corrente não aceita a ideia de haver políticas redistribuitivas patrocinadas pelo Estado, sendo que Nozick chega a descrever a teoria de Rawls como "um modelo de maná vindo do céu, como se as partes na posição original começassem por privar as pessoas das suas posses e a seguir as redistribuíssem segundo um ideal estrutural"65. Além disso, para que sejam implementadas essas políticas redistributivas, o Estado teria que in-

61 RAWLS, John. Uma teoria da justiça. São Paulo: Martins Fontes, 2000. p. 47/48.

62 Cf. KUKATHAS, Chandran; PETTIT, Philip. Raw/s: uma teoria da justiça e seus críticos..., p. 60/61.

63 GARGARELLA, Roberto. As teorias da justiça depois de Raw/s: um breve manual de filosofia política..., p. 26.

64 Cf. RAWLS, John. Uma teoria da justiça..., p. 16.

65 KUKATHAS, Chandran; PETTIT, Philip. Raw/s: uma teoria da justiça e seus críticos..., p. 104. 
tervir continuamente na vida das pessoas, o que seria intolerável sob o ponto de vista dos liberais clássicos. Por outro lado, na teoria da justiça como equidade, compreende-se que as pessoas somente conseguirão exercer suas liberdades civis se houver um mínimo necessário e suficiente de nível de vida, por meio de bens como educação, saúde, habitação, etc.

Diante de fatos naturais, em que certa pessoa nasce em família pobre ou rica, possuindo um talento especial que o diferencia dos outros, Rawls entende ser essa situação moralmente arbitrária, baseada tão somente em acasos da natureza. A ideia defendida é de que "cada um deve aceitar pagar o preço das escolhas para as quais tende: no ideal da concepção liberal; os indivíduos devem ser consideradores responsáveis por suas ações, e não meras vítimas de seu destino, às quais o Estado sempre deve apoiar" ${ }^{\prime \prime 6}$. Contudo, ele não vem a condenar esses acasos naturais, mas apenas propõe uma avaliação de como as instituições básicas deveriam atuar na sociedade. Rawls busca demonstrar que a teoria da justiça como equidade visa impedir com que essas vantagens naturais ou circunstanciais sejam tomadas como trunfos para alcançar ou justificar beneficios econômicos e políticos ${ }^{67}$ e eliminar as desigualdades na distribuição de vantagens e beneficios pelas instituições sociais. Em outras palavras, visa barrar a influência acidentais vindas do passado sobre a definição dos princípios que irão reger a estrutura da sociedade. O modo de evitar tal situação seria garantir o sistema procedimental puro, sendo que o Estado deverá respeitar as escolhas feitas pelos indivíduos, em que não deve o Estado, segundo Carlos Nino, "interferir nessa escolha ou adoção, limitando-se a projetar instituições que facilitem a busca individual desses planos de vida e satisfações dos ideais de virtude que cada um defende, e impedindo a interferência mútua no decorrer de sua busca" ${ }^{168}$. Contudo, é importante que se comente que, ao contrário do liberalismo clássico, o liberalismo igualitário considera como importante a liberdade positiva.

Somente os princípios da justiça serão comuns ou invariáveis, enquanto os planos de vida de cada indivíduo são variáveis um para o outro, sendo que cada qual terá objetivos diferentes. Em linhas gerais, pode haver conflitos de interesses quanto aos meios de repartição dos benefícios e deveres na sociedade, mas se torna necessário utilizar os princípios para descobrir qual seria o meio de distribuição apropriada para concretização da cooperação social.

A ideia da teoria de justiça como equidade em Rawls denota que a cooperação social irá estender à sociedade a possibilidade de escolha para cada indivíduo, de modo que não haja escolhas pelo grupo, mas haveria um respeito pelas escolhas de cada indivíduo. Somente o próprio indivíduo possui conheci-

66 GARGARELLA, Roberto. As teorias da justiça depois de Rawls: um breve manual de filosofia política..., p. 27.

67 RAWLS, John. Justiça e democracia..., p. 219.

68 NINO, Santiago Carlos. El constructivismo ético. Madrid: Centro de Estudios Constitucionales, 1989. p. 204. 
mento de suas necessidades e objetivos, sendo capaz de planejar seu plano de vida, num grau de certa racionalidade deliberativa ${ }^{69}$, garantindo a eficácia de um bem primário: a autoestima.

A forma "procedimental pura", prevista na teoria da justiça como equidade, visa garantir a individualidade da pessoa, evitando que o indivíduo seja refém das "fortes covicções da maioria, se forem de fato meras preferências sem nenhum fundamento nos princípios da justiça anteriormente estabelecidos, não tem peso algum ${ }^{\prime \prime 70}$. Isso significa que poderá haver objeção contra a maioria, com base nos princípios da justiça, no momento em que a conduta das instituições públicas estiver contrariando esses postulados ${ }^{71}$.

Assim, Rawls defendeu que a justiça como equidade seria uma espécie de justiça que cria seu próprio apoio, através da qual são "garantidas as liberdades a todas as pessoas e o próprio princípio da diferença garante que todos beneficiam da cooperação social"72. Esse princípio representa uma forma de compreender a distribuição de valores naturais como um bem comum, que deverá ser partilhado por todos os membros de uma sociedade. Esse entendimento separa Rawls da concepção liberal clássica, na medida em que a escola liberal defende que esta quebra de individualidade representaria uma ofensa a inviolabilidade das pessoas, tratando-as como um meio e não como um fim (quebra do imperativo de Kant).

Nessa linha, pode-se notar que a teoria de justiça não visa recompensar a virtude; funcionaria como um estímulo à aprendizagem, desenvolvendo a capacidade humana para o fim de promover o interesse comum. Para isso, Rawls compreende que, "se uma sociedade se organizasse tendo como seu primeiro princípio o objectivo de compensar o mérito moral, seria como criar a instituição da propriedade com o objectivo de punir ladrões. O critério de dar a cada um segundo a sua virtude' não seria, portanto, escolhido na posição original"73.

Dessa forma, a teoria de justiça de Rawls fornece um entendimento acerca de como as instituições sociais deveriam se comportar na sociedade, para o fim de atender aos postulados da liberdade e igualdade dos cidadãos, e consequentemente seja um sistema justo. Enquanto que na meritocracia prevalecem os atributos sobre a pessoa, a teoria de Rawls busca resgatar o valor do indivíduo.

Cf. RAWLS, John. Uma teoria da justiça..., p. 463.

RAWLS, John. Uma teoria da justiça..., p. 499.

Cf. KUKATHAS, Chandran; PETTIT, Philip. Raw/s: uma teoria da justiça e seus críticos..., p. 66.

KUKATHAS, Chandran; PETTIT, Philip. Rawls: uma teoria da justiça e seus críticos..., p. 62.

RAWLS, John. Citado por SANDEL, Michael. O liberalismo e os limites da justiça. Lisboa: Fundação Calouste Gulbenkian, 2005. p. 127. 


\section{III - A IMPLEMENTAÇÃO DOS DIREITOS PRESTACIONAIS-SOCIAIS COMO CONDIÇÃO DA DIGNIDADE DA PESSOA HUMANA}

Conforme foi comentado, se no início da construção do Estado de Direito houve a implementação de um modelo de esquema formal, com o passar do tempo essa legalidade formal e a neutralidade estatal foi sendo substituída por um Estado solidário ou providencial. A partir desse momento, o Estado assume o encargo de buscar uma reconfiguração de sua atuação na sociedade, passando a ter o compromisso para com o bem-estar social. A partir daí emerge como problema a identificação de como as instituições públicas e privadas deverão se portar frente aos direitos sociais, eis que a Constituição Federal 1988 traz um rol bastante significativo dessa espécie de direitos, como, por exemplo: a educação, a saúde, o trabalho, a moradia, o lazer, a segurança, a previdência social, a proteção à maternidade e à infância, a assistência aos desamparados, etc. (art. $\left.6^{\circ}\right)$.

De antemão, pode-se verificar que a atuação estatal fica vinculada aos objetivos da República Federativa do Brasil previstos no art. 3o, III, da Constituição Federal, em especial aquele que determina: "erradicar a pobreza e marginalização e reduzir as desigualdades sociais e regionais", impondo como dever do Estado a promoção de medidas sociais. Isso deixa claro que a implementação dos direitos econômicos, sociais e culturais ficará vinculada à prática de ações estatais, de modo que deverá haver uma teoria de justiça que fundamente e oriente como se dará essa atuação, sob pena de se verificar uma deslegitimidade constitucional.

É evidente que a Constituição Federal de 1988 incorporou uma ideologia solidária ou providencial - não há dúvidas a este respeito -, mas o operador do direito precisa ir além desse entendimento, na medida em que se torna necessário encontrar a legitimidade para que o Estado pratique condutas em nome dessa solidariedade. Em uma linguagem mais direta, fazem-se as seguintes indagações a título de exemplo: há fundamento constitucional para aprovações de leis de tratamentos diferenciados como cotas raciais em universidades públicas, Estatuto do Idoso, lei que proíbe fumo em lugares públicos fechados ou, até mesmo, proibição de comercialização de frituras em escolas públicas?

Continuamente é invocado o interesse público para justificar medidas que venham a suprimir a vontade individual, isso em prol de um bem comum. Mas Hebert Marcuse, em conferência proferida na Universidade do Kansas, faz uma interessante indagação: "Quem determina o interesse geral de uma coletividade e, assim sendo, o alcance e os limites da liberdade e da felicidade individuais e os sacrifícios impostos à liberdade e à felicidade individuais em nome e no interesse da coletividade?"74

74 MARCUSE, Herbert. Ética e revolução. In: MARCUSE, Herbert. Cultura e sociedade. Trad. Leo Maar de Wolfgang. Maria Loureiro Isabel e Robespierre de Oliveira. São Paulo: Paz e Terra, v. 2, 1998. p. 137. 
A história do direito relata que a constituinte de 1987 foi fruto de um intenso processo de debates e propostas, em que os mais variados grupos sociais opinaram e conseguiram valer seus interesses. Com isso, a principal fonte do processo constituinte foram as audiências públicas em que diversos grupos sociais, como juristas, doutrinadores, cidadãos, conseguiram apresentar suas propostas. Tanto foi assim que o resultado deste trabalho foi batizado de "Constituição Cidadã, na expressão de Ulysses Guimarães, Presidente da Assembleia Nacional Constituinte que a produziu, porque teve ampla participação popular em sua elaboração e especialmente porque se volta decididamente para a plena realização da cidadania"175. Isso ajudou com que a Constituição tivesse participação das mais variadas classes sociais, fruto de um pluralismo jurídico, acompanhando a tendência do Estado moderno que surge com uma filosofia diferente, de modo que o ordenamento jurídico passe a aceitar as ordens jurídicas insurgentes, pertencentes ao convívio social ${ }^{76}$.

Quanto ao direito à educação, o art. 208, inciso V, da Constituição Federal dispõe que o ingresso no ensino superior possui regulamentação que determina que haverá o "acesso aos níveis mais elevados do ensino, da pesquisa e da criação artística, segundo a capacidade de cada um", o que, aparentemente, impõe um caráter meritório na admissão de acadêmicos, ao contrário do que ocorre que ensino fundamental e médio, que se orientam pelo princípio da universalização. Essa é uma discussão recente que pode ser travada à luz do princípio da justiça da Constituição Federal de 1988, pois existem discussões jurídicas e políticas, como as cotas raciais em universidades, que envolvem a questão de como o Estado deve se portar diante desse impasse constitucional. O resultado dessa dúvida servirá de embasamento para a legitimação das políticas governamentais.

É possível perceber que há entendimentos dos mais variados sentidos, mas é necessário interpretar o espírito constitucional e a teoria da justiça adotada pela Constituição Federal de 1988, com a finalidade de obter a resposta mais adequada à situação apresentada.

O que se quer chamar atenção não seria a respeito do mérito da discussão (cotas raciais no ensino superior), mas sim a necessidade de se identificar a teoria de justiça que embasa a Carta da República. É possível identificar alguns entendimentos sobre a aplicação do art. 208 da CF, como, por exemplo, aqueles que defendem haver uma exigência de caráter meritório, ou seja, somente haverá acessão acadêmica para quem exercer um esforço intelectual ${ }^{77}$, sendo este, também, o entendimento encontrado em algumas decisões judiciais ${ }^{78}$. Por

75 SILVA, José Afonso da. Curso de direito constitucional positivo. 16. ed. São Paulo: Malheiros, 1998. p. 92.

76 MALISKA, Marcos Augusto. Pluralismo jurídico e direito moderno. Curitiba: Juruá, 2000. p. 108.

77 RANIERI, Nina Beatriz Stocco. A reserva de vagas nas universidades públicas. BDA: Boletim de Direito Administrativo, São Paulo, v. 17, n. 9, p. 699-701, 2001.

78 Essa questão foi debatida no Tribunal Regional Federal da $2^{\text {a }}$ Região, ao se julgar o Agravo de Instrumento $n^{\circ}$ 2008.02.01.012162-1, ocasião em que a Desembargadora Vera Lúcia Lima decidiu que as cotas raciais não 
outro lado, este mesmo dispositivo constitucional pode ser interpretado como uma ação afirmativa destinada a promover a igualdade de acesso à educação (art. $3^{\circ}$, III, da $\mathrm{CF}^{79}$ ), medida intermediária para se alcançar a justiça distributiva. Para Joaquim Barbosa, as ações afirmativas em prol dos negros seria "a melhor forma de correção e de reparação desse estado de coisas consistiria em aumentar (via ações afirmativas) as chances dessas vítimas históricas de obterem os empregos e as posições de prestigio que elas naturalmente obteriam caso não houvesse discriminação" ${ }^{\prime \prime 0}$.

Outro assunto que assola a jurisprudência brasileira é a respeito da transfusão de sangue de pessoas pertencentes à religião de testemunhas de Jeová, pois estes fiéis acreditam que constitui uma ofensa à moral de sua religião aceitar uma transfusão de sangue ${ }^{81}$. O Tribunal de Justiça de São Paulo, ao contrário, restringindo a autonomia privada, ou seja, o desejo de seguir à fé religiosa teve que ceder em prol ao direito à vida. Mas o detalhe importante é de que o Estado coercitivamente impôs esse resultado, anulando a vontade das pessoas (autonomia privada). A indagação que automaticamente se faz é: poderia o Estado fazer escolhas em nome do indivíduo? Como poderia ser compreendida a busca à felicidade dentro no cenário jurídico-constitucional?

No julgamento do Recurso Extraordinário no 477554, o Supremo Tribunal Federal definiu que a busca da felicidade seria um princípio implícito do constitucionalismo brasileiro, devendo ser compreendido como elemento essencial da dignidade da pessoa humana:

O princípio constitucional da busca da felicidade, que decorre, por implicitude, do núcleo de que se irradia o postulado da dignidade da pessoa humana, assume papel de extremo relevo no processo de afirmação, gozo e expansão dos direitos fundamentais, qualificando-se, em função de sua própria teleologia, como fator de neutralização de práticas ou de omissões lesivas cuja ocorrência possa comprometer, afetar ou, até mesmo, esterilizar direitos e franquias individuais. Assiste, por isso mesmo, a todos, sem qualquer exclusão, o direito à busca da felicidade, verdadeiro postulado constitucional implícito, que se qualifica como expressão de uma ideia-força que deriva do princípio da essencial dignidade da pessoa humana. Precedentes do Supremo Tribunal Federal e da Suprema Corte americana. ${ }^{82}$

Em outras situações, a Suprema Corte também reconheceu a busca da felicidade como fundamento do constitucionalismo brasileiro, tendo em vista fun-

atendiam ao princípio da isonomia, haja vista que o acesso ao ensino universitário deve sempre ser regulado de acordo com o critério meritório.

79 "Art. $3^{\circ}$ Constituem objetivos fundamentais da República Federativa do Brasil: [...] III - erradicar a pobreza e a marginalização e reduzir as desigualdades sociais e regionais."

80 GOMES, Joaquim B. Barbosa. Ação afirmativa \& princípio constitucional da igualdade: o direito como instrumento de transformação social. A experiência dos EUA. Rio de Janeiro: Renovar, 2001. p. 63/64.

81 Brasil. TJSP, AP 1234304400, 3ª C., Rel. Flavio Pinheiro, Registro 18.06.2002.

82 Brasil. STF, RE 477554, Rel. Celso de Mello, J. 16.08.2011. 
cionar como uma emancipação do ser humano diante do Estado ${ }^{83}$. Situações de extrema relevância foram decididas pelo Judiciário brasileiro, até mesmo acerca do início da vida humana para fins de aplicação dos direito de personalidade. E certamente todos esses assuntos possuem, como fundamento constitucional, a busca à felicidade e justiça, pois de nada serviria a Separação dos Poderes, Constituição ou Estado que não seja para a garantia da dignidade da pessoa humana e felicidade dos seres.

É possível perceber que existem os mais variados entendimentos, sendo que alguns se identificam com o liberalismo clássico, outros com o liberalismo igualitário. Certamente a corrente liberal clássica iria utilizar algum argumento de que não seríamos responsáveis pela pobreza, pela fome ou pela mortalidade ${ }^{84}$; por conta disso, não poderíamos carregar o fardo de arcar com políticas distributivas. Ocorre que o próprio texto constitucional expressamente adotou princípios que buscam demonstrar a "ideologia" inspiradora da sociedade, e, como entende Gilberto Bercovici: "Os princípios fundamentais são diretamente aplicáveis, funcionando como critério essencial de interpretação e de integração, dando unidade e coerência a todo o sistema constitucional [...] configuram o núcleo irredutível da Constituição, que não pode ter suas normas interpretadas isoladamente" ${ }^{\prime \prime 85}$.

Na égide do atual Estado Social, não se pode estabelecer um sistema em que a liberdade irá prevalecer definitivamente sobre a igualdade, pois o pensamento jurídico contemporâneo é a favor de um Estado solidário, um Estado que intervém na sociedade para garantir a igualdade de oportunidades para todas as pessoas e não somente da maioria. Dessa maneira, no Estado social, a igualdade surge como uma técnica de saneamento de diferenças, isto é, um instrumento de combate as desigualdades sociais existentes na sociedade. E, para que a Constituição Federal de 1988 seja efetiva, deve impor respeito aos cidadãos, o que demonstra que toda política constitucional repousa não somente em aceitá-la, mas sim em senti-la e obedecê-la. É nesse sentido que Pablo Lucas Verdú salienta a importância de se levar em conta a manutenção do sentimento constitucional, ou seja, "é a convicção emocional, intimamente vivida por um grupo social, sobre sua crença na justiça e na equidade do ordenamento positivo vigente, que motiva a adesão em relação a este e o rechaço ante sua transgressão"86. É por isso que se deve aproveitar este momento histórico constitucional vivido pelo Brasil, situação em que a Ministra Cármen Lúcia, em voto proferido na ADln 2649/DF, afirmou: "Já não se pensa ou age segundo o ditame de 'a cada um o que é seu', mas 'a cada um segundo a sua necessidade'. E a

83 Brasil. STF, ADIn 3510, Tribunal Pleno, Rel. Min. Carlos Ayres Britto, J. 29.05.2008.

84 VITA, Álvaro. A justiça igualitária e seus críticos..., p. 220/201.

85 BERCOVICI, Gilberto. A problemática da constituição dirigente: algumas considerações sobre o caso brasileiro. Revista de Informação Legis/ativa, Brasília, a. 36, n. 142, p. 45/46, abr./jun. 1999.

86 VERDÚ, Pablo Lucas. O sentimento constitucional: aproximação ao estudo do sentir constitucional como modo de integração política. Trad. Agassez Almeida Filho. Rio de Janeiro: Forense, 2006. p. 69. 
responsabilidade pela produção destes efeitos sociais não é exclusiva do Estado, senão que de toda sociedade" ${ }^{\prime 87}$. Isso mostra que o espírito solidário é um dos objetivos da cidadania constitucional, sendo, através dela, que os institutos jurídicos devem ser refletidos e aplicados.

Se a Carta da República foi elaborada sob um intenso debate pluralista, e seu texto envolve um conjunto de valores, é obvio que para sua concretização haverá necessidade de analisar o debate constitucional como ordem normativa positiva. Mas não poderá o operador jurídico deixar de averiguar as circunstâncias sociais que giram em torno da discussão, sob pena do empobrecimento do debate. Deve-se entender que "o homem mesmo deve produzir uma comunidade comunitária, e precisa, além dos impulsos sociais naturais, um momento de racionalidade prática, e ainda um estágio bem avançado do desenvolvimento cultural" ${ }^{\prime \prime}$. Isso mostra que, para construção de uma sociedade, o homem será o corresponsável e não o meio (instrumento) ou objeto; deverá ele ser tratado como sujeito do desenvolvimento. Nesse sentido, concorda-se com o posicionamento de Carlos Ayres Britto, quando afirma que "todo ser humano não é somente parte de algo, mas algo à parte. Não apenas parte de um todo, mas um todo à parte" ${ }^{\prime 89}$. Por isso, acredita-se que, ao mesmo tempo em que o indivíduo deve agir como um membro da sociedade, possuindo um espírito solidário, também devem existir meios para que a sociedade respeite a identidade (objetivos pessoais) deste indivíduo, dentro dos objetivos constitucionais (direito à diferença). É diante deste cenário que se compreende o tratamento que a Constituição Federal de 1988 fornece aos direitos prestacionais, tendo em vista que esta Carta Constitucional vem trazer um novo referencial para o ordenamento jurídico brasileiro, possibilitando um novo projeto de sociedade. A atual ordem constitucional não se resume a meras normas que fixam competências e ordenam o poder estatal, mas, sim, vai além disso, enunciando metas, programas a serem realizados pelo Estado.

O Estado assumiu o compromisso, como agente protagonista, de implementar os direitos prestacionais-sociais. A ordem constitucional brasileira identificou que somente a partir da concretização dos direitos básicos é que os cidadãos terão condições de exercer seus direitos civis e de ver reconhecida sua dignidade social. O Estado deverá colocar os meios jurídicos e materiais necessários à disposição dos cidadãos, com fim de possibilitar que eles tenham condição real do exercício dos direitos constitucionais. A finalidade dos direitos denominados de prestacionais estrito sensu fundamenta o dever das instituições públicas de buscarem concretizar uma ordem social justa, ou seja, busca impor

87 Brasil. STF, Tribunal Pleno, voto Ministra Cármen Lucia Antunes Rocha, ADIn 2649/DF, J. 08.05.2008, Publicação: DJe-197 Divulg. 16.10.2008, Public. 17.10.2008. LEXSTF v. 30, n. 358, p. 34-63, 2008.

88 HÖFFE, Otfried. Justiça política: fundamentação de uma filosofia crítica do Direito e do Estado. Trad. Ernildo Stein. Petrópolis: Vozes, 1991. p. 218.

89 BRITTO, Carlos Ayres. Teoria da Constituição. Rio de Janeiro: Forense, 2003. p. 189. 
ao Estado a tarefa de compensar os déficits da garantia jurídico-fundamental da liberdade ${ }^{90}$.

\section{CONSIDERAÇÕES FINAIS}

Por meio dos marcos teóricos apresentados e da prática judiciária, observa-se que a Constituição Federal de 1988, devido a sua origem pluralista, não adotou uma ou duas teorias de justiça, mas várias, de modo que elas foram conjugadas para um ideal de reconstrução democrática cidadã brasileira.

Não se pode defender o extremismo de se adotar a teoria liberal ou outra em sua integralidade, mas sim orientar o processo hermenêutico por meio da noção aristotélica do meio-termo, mediante a proporção ${ }^{91}$, verificando a atual realidade social, da qual o direito constitucional não poderá se desprender, pois deve-se compreender que a sociedade é fruto da construção humana, destinada a não somente proteger as liberdades dos indivíduos, mas também para permitir que este mesmo indivíduo possa atingir sua plenitude ${ }^{92}$.

Como destaca Nadir Pichler, muito além de uma reunião quantitativa, a sociedade tem um dever moral de convivência recíproca ${ }^{93}$. Por isso, ao mesmo tempo em que o indivíduo deve agir como um membro da sociedade, deve a sociedade respeitar seus objetivos individuais, desde que estes atendam aos primados do modelo do Estado Constitucional de Direito. Observe-se que a Carta Constitucional brasileira de 1988 não estabeleceu nenhuma ordem jurídica neutra; pelo contrário, os direitos fundamentais deverão ser interpretados como uma ordem axiológico-objetiva. O comprometimento social que se identificou na formulação da ordem constitucional também deve ser propiciado na aplicação dos direitos escolhidos, de modo que o Estado busque respeitar a real vontade popular, mas sem desvirtuar os postulados do ordenamento jurídico que foram criados como proteção do próprio sistema.

Apesar da existência de um rol significativo de direitos na Carta Constitucional, as políticas sociais praticadas no Brasil ainda estão muito precárias, longe de atingir todos os cidadãos de forma eficiente. Isso retrata uma profunda desigualdade social e dominação por parte de elites econômicas ${ }^{94}$. É por isso e outros motivos que Cármen Lúcia Antunes Rocha defendeu que, embora o

90 Cf. HESSE, Konrad. Temas fundamentais do direito constitucional. Trad. Carlos dos Santos Almeida. São Paulo: Saraiva, 2009. p. 52.

91 ARISTÓTELES. Ética a Nicômacos. São Paulo: Abril Cultural e Industrial S.A., 1973. p. 1095b.

92 Cf. HÖFFE, Otfried. Justiça política: fundamentação de uma filosofia crítica do Direito e do Estado. Petrópolis: Vozes, 1991. p. 215

93 PICHLER, Nadir Antônio. Citada por GABARDO, Emerson. Interesse Público e subsidiariedade: o Estado e a sociedade civil para além do bem e do mal. Belo Horizonte: Fórum, 2009. p. 345.

94 CHAUÍ, Marilena. Convite à filosofia. São Paulo: Ática, 1995. p. 436. 
Brasil possua uma ótima Constituição, o país tem uma péssima prática constituciona $\left.\right|^{95}$.

Esta pesquisa dirigiu-se ao resultado de que a felicidade dos cidadãos está ligada de alguma forma com a plenitude da dignidade da pessoa humana, que, por sua vez, se compõe da realização da liberdade e da igualdade. E a missão do Estado é combater as desigualdades políticas, fortalecendo a vida digna de seus cidadãos, o que torna mais desafiante o caminho da implementação dos direitos prestacionais-sociais. E a ordem constitucional inaugurada em 1988 criou mecanismos que visam corrigir essas desigualdades sociais. O que leva a defender que a dignidade da pessoa humana impulsiona a existência de um Estado interventor extremamente comprometido com a concretização destes direitos, mediante a exigência de uma atuação eficiente da Administração Pública e a ampliação da jurisdição constitucional como sua garantia.

Portanto, é de se entender a teoria da justiça da Constituição Federal de 1988 segue parâmetros disciplinados expressamente no seu preâmbulo: "[...] Estado Democrático, destinado a assegurar o exercício dos direitos sociais e individuais [...] e a justiça como valores supremos de uma sociedade fraterna", de modo que possibilite uma construção comunitária justa e fraterna.

\section{REFERÊNCIAS}

ARISTÓTELES. Política. Trad. Torrieri Guimarães. São Paulo: Martins Fontes, 2001. Ética a Nicômacos. Trad. Leonel Vallandro e Gred Borheim. São Paulo: Abril

Cultural e Industrial S.A., 1973.

BARROSO, Luís Roberto. Temas de direito constitucional. Rio de Janeiro: Renovar, t. II, 2003.

BERCOVICl, Gilberto. A problemática da constituição dirigente: algumas considerações sobre o caso brasileiro. Revista de Informação Legislativa, Brasília, a. 36, n. 142, abr./jun. 1999, p. 35-51.

BRASIL. Assembleia Nacional Constituinte (1987). O processo histórico de elaboração do texto constitucional: mapas demonstrativos. Trabalho elaborado por Dílson Emilio Brusco e Ernani Valter Ribeiro. Brasília: Câmara dos Deputados, Centro de Documentação e Informação, Coordenação de Publicações, 1993.

BRITTO, Carlos Ayres. Teoria da Constituição. Rio de Janeiro: Forense, 2003.

CAMPBELL, Tom. La Justicia: los principales debates contemporáneos. Barcelona: Gedisa, 2002.

CANOTILHO, José Joaquim Gomes. Constituição dirigente e vinculação do legislador. Coimbra: Coimbra, 2001.

CITTADINO, Gisele. Pluralismo, direito e justiça distributiva - Elementos da filosofia constitucional contemporânea. Rio de Janeiro: Lumen Juris, 2000. 
DINIZ, Antonio Carlos de Almeida. Teoria da legitimidade do direito e do Estado: uma abordagem moderna e pós-moderna. São Paulo: Landy, 2006.

DWORKIN, Ronald. A virtude soberana: a teoria e a prática da igualdade. Trad. Jussara Simões. São Paulo: Martins Fontes, 2005.

GALLUPO, Marcelo Campos. Igualdade e diferença - Estado Democrático de Direito a partir do pensamento de Habermas. Belo Horizonte: Mandamentos, 2002.

GABARDO, Emerson. Interesse público e subsidiariedade: o Estado e a sociedade civil para além do bem e do mal. Belo Horizonte: Fórum, 2009.

GARGARELLA, Roberto. As teorias da justiça depois de Rawls: um breve manual de filosofia política. Trad. Alonso Reis Freire. Rev. Trad. Elza Maria Gasparotto. São Paulo: Martins Fontes, 2008.

GOMES, Joaquim B. Barbosa. Ação afirmativa \& princípio constitucional da igualdade: o direito como instrumento de transformação social. A experiência dos EUA. Rio de Janeiro: Renovar, 2001.

GOMEZ, Manuel Herrera. Liberalismo versus comunitarismo: seis voces para um debate e una proposta. Navarra: Arazandi, 2007.

HÄBERLE, Peter. Hermenêutica constitucional - A sociedade aberta dos intérpretes da Constituição: contribuição para a interpretação pluralista e "procedimental" da Constituição. Porto Alegre: Sérgio Antonio Fabris, 1997.

HAYEK, Friedrich August Von. Os fundamentos da liberdade. Brasília: UnB, São Paulo: Visão, 1983.

HÖFFE, Otfried. Justiça política: fundamentação de uma filosofia crítica do Direito e do Estado. Trad. Ernildo Stein. Petrópolis: Vozes, 1991.

KELSEN, Hans. O que é justiça? A justiça, o direito e a política no espelho da ciência. Trad. Luís Carlos Borges. 3. ed. São Paulo: Martins Fontes, 2001.

KUKATHAS, Chandran; PETTIT, Philip. Rawls: uma teoria da "justiça" e seus críticos. Trad. Maria Carvalho. Lisboa: Gradiva, 1995.

KYMLICKA, Will. Filosofia política contemporânea: uma introdução. Trad. Luís Carlos Borges. Rev. Trad. Marylene Pinto Michael. São Paulo: Martins Fontes, 2006.

MALISKA, Marcos Augusto. Pluralismo jurídico e direito moderno. Curitiba: Juruá, 2000.

OLIVEIRA, Mauro Márcio. Fontes de informações sobre a Assembleia Nacional Constituinte de 1987: quais são, onde buscá-las e como usá-las. Brasília: Senado Federal, Subsecretaria de Edições Técnicas, 1993.

MARCUSE, Herbert. Cultura e sociedade. Trad. Leo Maar de Wolfgang. Maria Loureiro Isabel e Robespierre de Oliveira. São Paulo: Paz e Terra, v. 2, 1998.

MENDES, Gilmar Ferreira; COELHO, Inocêncio Mártines; BRANCO, Paulo Gustavo Gonet. Curso de direito constitucional. 4. ed. São Paulo: Saraiva, 2009.

NOVAIS, Jorge Reis. Contributo para uma teoria do Estado de direito: do estado de direito liberal ao Estado social e democrático de direito. Coimbra: Coimbra, 1987. NINO, Santiago Carlos. El constructivismo ético. Madrid: Centro de Estudios Constitucionales, 1989.

PLATÃO. A república. Trad. Enrico Corvisieri. São Paulo: Nova Cultural, 1992. 
RAWLS, John. Uma teoria da justiça. Trad. Almiro Pisetta e Lenita M. R. Esteves. São Paulo: Martins Fontes, 1997.

Justiça e democracia. Trad. Irene Paternot. São Paulo: Martins Fontes, 2000. ROSS, Alf. Direito e justiça. Trad. Edson Bini. Bauru: Edipro, 2000.

SANDEL, Michael. O liberalismo e os limites da justiça. Lisboa: Fundação Calouste Gulbenkian, 2005.

TAYLOR, Charles. Argumentos filosóficos. Trad. Adail Ubirajara Sobral. São Paulo: Loyola, 2000.

VIANNA, Luiz Werneck et al. A judicialização da política e das relações sociais no Brasil. Rio de Janeiro: Revan, 1999.

SILVA, José Afonso da. Curso de direito constitucional positivo. 16. ed. São Paulo: Malheiros, 1998.

VITA, Álvaro de. A justiça igualitária e seus críticos. 2. ed. São Paulo: Martins Fontes, 2007.

ZAGREBELSKI, Gustavo. El derecho dúctio. Madrid: Trotta, 1995. 